\title{
Distinct breakfast patterns on satiety perception in individuals with weight excess
}

Aichah Ahmad El Orra', Milena Monfort Pires', Sandra Roberta G. Ferreira'

\begin{abstract}
Objectives: Western dietary pattern predisposes to weight gain, insulin resistance and cardiometabolic diseases. Promoting satiety via modifications in diet composition could be useful to fight weight gain. Mediterranean diet which is recognized to be cardioprotective contains high fiber and unsaturated fat contents. We compared the effects of distinct breakfast patterns on satiety of individuals at cardiometabolic risk, and examined the correlation of satiety level after each breakfast intervention period with glucose parameters. Materials and methods: In this 10-week cross-over clinical trial, 54 individuals with weight excess were submitted to 2 types of 4-week isocaloric breakfasts (2-week washout), one typically Brazilian and a modified one, differing concerning fiber and types of fatty acids contents. Clinical data were collected before and after each breakfast. A satiety scale was applied at fasting and 10, 30 and 120' after breakfast consumption. Repeated measures ANOVA, Student $t$ test or non-parametric correspondents were used; correlations were tested by Pearson or Spearman coefficients. Results: Anthropometric variations after breakfasts were not significant. Only after the modified breakfast, reduction in blood pressure levels was observed. The satiety level did not show significant variation across each period or between the breakfasts. Non-significant correlation between satiety and glucose, insulin and HOMA-IR values after each intervention period was observed. Conclusion: We conclude that different breakfast compositions do not alter satiety level, which is not correlated to glucose parameters in overweight individuals. Stronger modifications of daily meals might be necessary to differentiate satiety levels under distinct dietary patterns. Arch Endocrinol Metab. 2016;60(4):333-40
\end{abstract}

Keywords

Satiety; dietary pattern; fatty acids; cardiometabolic risk
${ }^{1}$ Departamento de Epidemiologia, Faculdade de Saúde Pública, Universidade de São Paulo (USP), São Paulo, SP, Brasil

Correspondence to: Sandra Roberta G. Ferreira Departamento de Epidemiologia, Faculdade de Saúde Pública, Universidade de São Paulo Av. Dr. Arnaldo, 715 01246-904 - São Paulo, SP, Brasil sandrafv@usp.br

Received on: Oct/24/2015 Accepted on Nov/1/2015

DOI: 10.1590/2359-3997000000133

\section{INTRODUCTION}

$\mathrm{H}$ abits of Western societies, including the Brazilian ones, have contributed to elevate the incidence of non-communicable chronic diseases, mostly due to the increase in body adiposity. As a consequence of current facilities for food consumption, individuals are consuming high-density high-fat and low-fiber foods, which characterize the typical Western pattern. Following the recognition of the deleterious impact of the high fat diet for metabolic disturbances that predispose to atherosclerosis $(1,2)$, evidences related to the benefits of dietary habits of Mediterranean populations on cardiovascular mortality have emerged $(3,4)$. Mediterranean dietary pattern is characterized by high content of monounsaturated fatty acids (MUFA), present in olive oil, and polyunsaturated fatty acids (PUFA), present in nuts and fish, as well as antioxidants minerals and polyphenols, present in vegetables, whole grains and wine. Considering the harms of saturated fat (SFA) and benefits of unsaturated fat on intracellular insulin signaling (5) and the results of dietary interventions $(4,6)$, the scientific society has accepted the Mediterranean-style diet as indicated for cardioprotection $(7,8)$.

Feeding-induced fullness is shown to be altered in obese individuals, and disturbances on the release and/or response to satietogenic substances following food intake were detected (9). How such disturbances contribute to weight gain is a matter of investigation. Satiety and hunger are regulated by multiple hormones (incretins, ghrelin, leptin, insulin, glucagon, somatostatin among others), which respond to nutrients present in the gastrointestinal tract that exert actions in hypothalamic neurons $(10,11)$. Diet characteristics may influence hormonal and metabolic signals to central nervous system, favoring food intake and a positive energy balance. Studies in rodents have contributed to understand the mechanisms by which hormones inform the hypothalamus about the body adiposity level as well as the molecular pathways involved in neurotransmitters 
expression that modulates hunger and satiety (12). In clinical settings, comparisons of satiety level in response to distinct compositions of meals, for instance, one typically Western and another including Mediterranean components were scarcely investigated. It is possible that satiety handling could help the weight control and, consequently, result in cardiometabolic benefits (13).

In general, elevations of post-prandial plasma glucose induce satiety, although the magnitude of this effect varies according to the meal composition (1416). A sharp rise in plasma glucose induced by simple carbohydrate consumption showed to be able to suppress satiety for a short duration, while the presence of fiber to prolong satiety (17). Despite evidence that dietary fat is more satietogenic than other nutrients, few data concerning differences in the perception according to its saturation grade of fatty acids are available (18). It is known that MUFA are more promptly oxidized than SFA, which could result in higher satietogenic power; however, in humans, studies are inconclusive (19).

Among the tools to assess satiety level reported by individuals following meal consumptions, the scale Satiety Labeled Intensity Magnitude - SLIM (20) has been proposed due to its simplicity, easy to use and sensitivity to quantify this perception in response to diverse composition of food intake. The SLIM shows good accuracy and enables better discrimination in comparison with others described (21).

Facing the perspective that knowledge on the impact of different dietary patterns in provoking satiety could contribute for the obesity control, this study aimed at comparing the satiety levels in response to two isocaloric breakfasts but with different compositions, one typically Western and one modified including Mediterranean components; also, at analyzing the correlation of satiety level after experimental periods of breakfast with plasma glucose, insulin and insulin resistance index.

\section{MATERIALS AND METHODS}

\section{Sample}

This study was approved by the School of Public Health Ethical Committee and conducted at the University of São Paulo Hospital. Individuals agreed and provided signed consent. The convenience sample was constituted by individuals aged 35 to 69 years, body mass index $(\mathrm{BMI}) \geq 25$ and $<40 \mathrm{~kg} / \mathrm{m}^{2}$, and at least one additional abnormality: concentration of triglycerides $\geq 150 \mathrm{mg} / \mathrm{dL}$ or total cholesterol $\geq 230$ $\mathrm{mg} / \mathrm{dL}$ or LDL-c $>100 \mathrm{mg} / \mathrm{dL}$ or fasting plasma glucose between 100 and $124 \mathrm{mg} / \mathrm{dL}$ or systolic blood pressure $\geq 140 \mathrm{mmHg}$. Exclusion criteria were use of medications that influence hunger or satiety, psychiatric disorders, pregnancy and body weight variation $>5 \%$ during the last six months.

\section{Protocol}

This was a 10-week cross-over clinical trial composed of two interventions in the breakfast, of 4-week duration each with a 2 -week washout period between them. The breakfasts were isocaloric (energy content of $480 \mathrm{kcal}$ ), but differing according to the fatty acids composition and fiber content. The called "Brazilian breakfast" was prepared including: whole milk (180 mL), coffee $(60 \mathrm{~mL})$, sugar (10 g), French bread (50 g), butter (15 g) and mozzarella cheese $(32 \mathrm{~g})$. The "modified breakfast" was created including some components of the Mediterranean diet as following: skim milk (180 mL), coffee $(60 \mathrm{~mL})$, sugar (10 g), whole-grain French bread (50 g), ricotta cheese $(40 \mathrm{~g})$ with virgin olive oil $(16 \mathrm{~g})$ and peanuts $(10 \mathrm{~g})$. These preparations resulted in the same content of total fat but differing by the relative amounts of fatty acids. Participants were oriented to maintain their daily intake during the day, as well as their regular physical activities. They weekly received phone calls in order to reinforce compliance to the experimental protocol.

One week prior the start of study, as well as at the last week of consumption of each breakfast, two 24-hour food records and the satiety scale were collected. One food record was obtained face-to-face and the other by telephone, by a trained dietitian, using the multiple pass method. The standardization of equivalences of house measures of consumption (in grams) was performed based on a Brazilian-tailored directory of recipes and measures previously described $(22,23)$. Dietary data were analyzed using the Virtual Nutri software. Energy intakes $<500 \mathrm{kcal}$ or $>5,000 \mathrm{kcal} /$ day were considered outliers and were excluded from analyses. Variables of interest for the present study were total energy intake (TEI), macronutrients, subtypes of fatty acids and total fiber intakes.

Level of satiety was assessed using the SLIM scale (20), in which the participant is asked to inform one of 11 conditions, distributed into a visual vertical line that ranges from "too full" until "too 
hungry". To each condition in this scale (available at http://www.sciencedirect.com/science/article/ pii/S0195666304001242) there is a correspondent numeric value (score of satiety). Negative values in the SLIM scale are indicative of hunger. Satiety data were obtained before and 10, 30 and 120 minutes after breakfast consumption.

Physical activity was evaluated using the short version of the International Physical Activity Questionnaire that was validated in Brazil (24), and was expressed in minutes per week.

At baseline and at the final of each intervention, anthropometric measurements, blood pressure and fasting blood samples were obtained for determinations of plasma glucose and insulin concentrations, employed for the calculation of insulin resistance index. Body mass index was obtained by the ratio of weight (in kilograms) to squared height (in meters). Waist circumference was taken in upright position during expiration, at midpoint between the last rib and iliac crest. Blood pressure was taken after resting for five minutes in sitting position with automated oscillometric device (Omron HEM712C, Omron Health Care, USA), three times, being the mean of the last two measurement the final values of systolic and diastolic blood pressure levels.

\section{Analytical methods}

Plasma glucose was determined by glucose oxidase method and insulin by enzyme-linked immunoenzymatic assay (AutoDelfia, Perkin Elmer Life Sciences Inc, Norton, OH, USA). These values were used to calculate HOMA-IR (homeostasis model assessment of insulin resistance), and used to estimate insulin resistance (25).

\section{Statistical analysis}

Data were expressed as mean and standard deviation or error. Log-transformation was applied for non-Gaussian variables for analysis purposes, and values were reported as back-transformed into their original units. Changes in dietary and clinical data before and after breakfasts were compared by Student $t$ test. The profiles of satiety score values across time after each breakfast were compared by repeated measures ANOVA. Correlations between variables were tested by Pearson or Spearman coefficients. P value $<0.05$ was considered significant. Statistical analysis was performed using the SPSS version 17.0 for Windows.

\section{RESULTS}

From 80 individuals, 54 completed both intervention periods of breakfasts. Among the dropouts there was a predominance of men. The frequency and doses of medications were maintained in the whole period, as well as the level of physical activity (data not shown). The sample was composed of $66 \%$ of women, with a mean age of $53.0 \pm 1.3$ years. As expected, participants had increased body mass index $\left(30.8 \pm 1.4 \mathrm{~kg} / \mathrm{m}^{2}\right)$. Table 1 shows that the mean values of waist circumference $(105.2 \pm 2.5$ versus $98.2 \pm 1.3 \mathrm{~cm}, \mathrm{p}<0.01)$ and blood pressure levels $(138.6 \pm 4.7$ versus $123.5 \pm 2.5 \mathrm{mmHg}$, $\mathrm{p}<0.01$ ) were higher in men, while HDL-c was higher in women $(57.0 \pm 2.3$ versus $44.4 \pm 2.0 \mathrm{mg} / \mathrm{dL})$. Satiety scores before and after breakfasts did not differ between sex, except for higher values in women than men after 10 minutes of the modified breakfast.

Table 1. Clinical data and satiety scores of 54 participants according to sex. Values are expressed in mean and standard deviation

\begin{tabular}{|c|c|c|c|}
\hline & $\begin{array}{c}\text { Men } \\
\mathrm{n}=18\end{array}$ & $\begin{array}{c}\text { Women } \\
n=36\end{array}$ & $\mathbf{p}$ \\
\hline \multicolumn{4}{|l|}{ Clinical data } \\
\hline Age (years) & $49.9 \pm 2.4$ & $54.6 \pm 1.5$ & 0.09 \\
\hline Body mass index $\left(\mathrm{kg} / \mathrm{m}^{2}\right)$ & $31.6 \pm 1.2$ & $30.4 \pm 0.8$ & 0.32 \\
\hline Waist circumference $(\mathrm{cm})$ & $105.2 \pm 2.5$ & $98.2 \pm 1.3$ & $<0.01$ \\
\hline Systolic blood pressure (mmHg) & $138.6 \pm 4.7$ & $123.5 \pm 2.5$ & $<0.01$ \\
\hline Diastolic blood pressure $(\mathrm{mmHg})$ & $80.4 \pm 3.0$ & $74.7 \pm 1.6$ & 0.07 \\
\hline Plasma glucose (mg/dL) & $98.9 \pm 2.6$ & $93.8 \pm 1.6$ & 0.09 \\
\hline Total cholesterol (mg/dL) & $202.4 \pm 11.0$ & $207.4 \pm 5.8$ & 0.67 \\
\hline $\mathrm{HDL}-\mathrm{c}(\mathrm{mg} / \mathrm{dL})$ & $44.4 \pm 2.0$ & $57.0 \pm 2.3$ & $<0.01$ \\
\hline LDL-c (mg/dL) & $121.4 \pm 9.8$ & $123.2 \pm 4.2$ & 0.84 \\
\hline Triglycerides (mg/dL) & $179.5 \pm 25.7$ & $133.9 \pm 9.6$ & 0.05 \\
\hline \multicolumn{4}{|l|}{ Satiety scores } \\
\hline \multicolumn{4}{|l|}{ Brazilian breakfast } \\
\hline Fasting & $-23.4 \pm 5.8$ & $-12.1 \pm 3.7$ & 0.10 \\
\hline 10 minutes & $73.3 \pm 5.7$ & $81.3 \pm 2.9$ & 0.17 \\
\hline 30 minutes & $54.2 \pm 7.1$ & $65.0 \pm 19.6$ & 0.12 \\
\hline 120 minutes & $23.7 \pm 10.1$ & $31.8 \pm 5.9$ & 0.50 \\
\hline \multicolumn{4}{|l|}{ Modified breakfast } \\
\hline Fasting & $-23.4 \pm 5.8$ & $-12.1 \pm 3.7$ & 0.10 \\
\hline 10 minutes & $69.2 \pm 3.7$ & $83.3 \pm 2.8$ & 0.04 \\
\hline 30 minutes & $57.7 \pm 26.5$ & $68.1 \pm 3.5$ & 0.11 \\
\hline 120 minutes & $14.9 \pm 9.1$ & $29.5 \pm 38.5$ & 0.20 \\
\hline
\end{tabular}

Dietary data at baseline and after Brazilian and modified breakfasts are shown in Table 2. Despite the orientation to maintain regular daily intake, increases 
in total energy (TEI) and fat intakes were verified in both interventions, which differed according to the distribution of types of fatty acids consumed (Figure 1).

As far as the Brazilian breakfast is concerned, in particular, the increase in TEI was due to higher SFA intake $(27.9 \pm 0.81$ versus $20.8 \pm 0.93 \mathrm{~g}$ after Brazilian and modified, respectively). Relatively to TEI, the consumption of SFA was elevated, in parallel with significant reductions in intakes of carbohydrates and proteins $(\mathrm{p}<0.05)$.

After modified breakfast, elevation in total fat was observed which occurred mainly due to increased MUFA and PUFA intakes. Similar to the intervention with Brazilian breakfast, reductions in relative intakes of carbohydrates and proteins $(\mathrm{p}<0.05)$ were found. Only in modified breakfast an increase in total fiber intake was found.

Table 2. Mean values ( \pm SEM) of intake of dietary variables before and after four weeks of Brazilian and modified breakfast

\begin{tabular}{|c|c|c|c|c|c|c|}
\hline & \multicolumn{3}{|c|}{ Brazilian } & \multicolumn{3}{|c|}{ Modified } \\
\hline & Before & After & P-value & Before & After & P-value \\
\hline Total energy intake (kcal/day) & $1871 \pm 66$ & $1678 \pm 83$ & 0.01 & $1743 \pm 81$ & $1770 \pm 48$ & 0.75 \\
\hline Carbohydrate (\% TEI) & $52.0 \pm 1.0$ & $48.9 \pm 0.9$ & 0.03 & $54.3 \pm 1.1$ & $48.2 \pm 0.7$ & $<0.01$ \\
\hline Protein (\% TEl) & $15.5 \pm 0.5$ & $14.2 \pm 3.2$ & 0.05 & $15.4 \pm 0.5$ & $14.3 \pm 0.4$ & 0.04 \\
\hline Total fat (\% TEl) & $32.5 \pm 0.9$ & $36.9 \pm 0.9$ & $<0.01$ & $30.3 \pm 0.9$ & $37.5 \pm 0.7$ & $<0.01$ \\
\hline Saturated fatty acids (\%TEI) & $9.9 \pm 0.4$ & $13.4 \pm 0.4$ & $<0.01$ & $9.1 \pm 0.4$ & $10.4 \pm 0.3$ & $<0.01$ \\
\hline MUFA (\% TEI) & $8.7 \pm 0.4$ & $9.3 \pm 0.3$ & 0.23 & $7.7 \pm 0.4$ & $13.8 \pm 0.4$ & $<0.01$ \\
\hline PUFA (\% TEl) & $4.8 \pm 0.3$ & $4.5 \pm 0.3$ & 0.05 & $4.3 \pm 0.3$ & $5.6 \pm 0.4$ & $<0.01$ \\
\hline Total fiber intake (g/day) & $12.5 \pm 0.6$ & $12.8 \pm 0.7$ & 0.73 & $12.9 \pm 0.8$ & $15.0 \pm 0.7$ & 0.04 \\
\hline
\end{tabular}

TEl: total energy intake; MUFA: monounsaturated fatty acids; PUFA: polyunsaturated fatty acids.
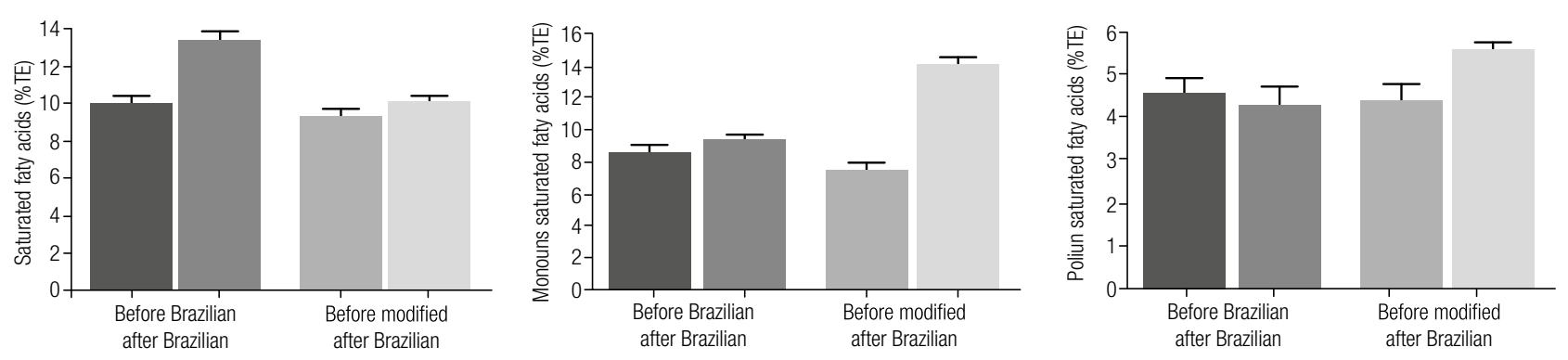

Figure 1. Changes in subtypes of fatty acids intake after intervention with Brazilian and modified breakfasts.

Table 3 shows values of clinical variables before and after breakfasts. No significant differences in anthropometric and biochemical variables were detected after the interventions.

After modified breakfast (Table 3), there is no variation in anthropometric measurements either; however, a significant increase in HDL-cholesterol concentration $(51.8 \pm 1.8$ versus $54.2 \pm 2.0 \mathrm{mg} / \mathrm{dL}$, $\mathrm{p}=0.03)$ and decrease in blood pressure levels were observed.

Figure 2 depicts mean values of satiety, before and after each breakfast period, showing similar profiles of the curves obtained.
Mean values of the satiety scores of participants, obtained following Brazilian and modified breakfast, are in Table 4. At fasting, as expected, participants referred negative values, indicative of hungry. Ten minutes from the consumption of both breakfasts, a significant elevation of scores was found with further gradual decrease across time (Table 4 and Figure 2). No difference in the satiety score profiles, obtained during the 120 minutes of each breakfast, was observed.

Associations of late satiety ( 30 e 120 minutes) with glicemia, insulinemia e HOMA-IR were tested, after breakfasts, but no significant correlation was detected (data not shown). 
Table 3. Mean values ( \pm SEM) of clinical variables before and after Brazilian and modified breakfasts

\begin{tabular}{|c|c|c|c|c|c|c|}
\hline & \multicolumn{3}{|c|}{ Brazilian } & \multicolumn{3}{|c|}{ Modified } \\
\hline & Before & After & p-value & Before & After & p-value \\
\hline Body mass index (kg/m²) & $30.2 \pm 0.6$ & $30.3 \pm 0.6$ & 0.14 & $30.3 \pm 0.6$ & $30.2 \pm 0.6$ & 0.23 \\
\hline Waist circumference (cm) & $99.8 \pm 1.3$ & $99.6 \pm 1.4$ & 0.54 & $100.2 \pm 1.3$ & $99.7 \pm 1.40$ & 0.11 \\
\hline Systolic blood pressure (mmHg) & $124.6 \pm 2.5$ & $123.4 \pm 2.0$ & 0.57 & $126.5 \pm 2.3$ & $123.5 \pm 2.2$ & 0.05 \\
\hline Diastolic blood pressure (mmHg) & $75.1 \pm 1.40$ & $73.8 \pm 1.8$ & 0.24 & $75.8 \pm 1.5$ & $73.3 \pm 1.5$ & 0.02 \\
\hline Fasting plasma glucose (mg/dL) & $95.6 \pm 1.1$ & $96.2 \pm 1.1$ & 0.42 & $95.3 \pm 1.6$ & $95.7 \pm 1.3$ & 0.78 \\
\hline Fasting insulin ( $\mu \mathrm{Ul} / \mathrm{mL})$ & $40.2 \pm 9.0$ & $40.5 \pm 5.5$ & 0.98 & $40.1 \pm 4.9$ & $52.4 \pm 5.5$ & 0.09 \\
\hline HOMA-IR & $8.9 \pm 2.0$ & $9.2 \pm 1.2$ & 0.89 & $8.9 \pm 1.1$ & $11.6 \pm 1.4$ & 0.11 \\
\hline Total cholesterol (mg/dL) & $206.0 \pm 5.7$ & $207.9 \pm 5.6$ & 0.52 & $205.6 \pm 5.8$ & $204.7 \pm 5.1$ & 0.78 \\
\hline HDL-c (mg/dL) & $55.3 \pm 1.8$ & $53.7 \pm 2.5$ & 0.09 & $51.8 \pm 1.8$ & $54.2 \pm 2.0$ & 0.03 \\
\hline LDL-c (mg/dL) & $123.6 \pm 4.4$ & $121.7 \pm 4.5$ & 0.40 & $121.6 \pm 4.4$ & $121.4 \pm 4.0$ & 0.94 \\
\hline Triglycerides (mg/dL) & $149.8 \pm 13.0$ & $154.2 \pm 10.5$ & 0.56 & $151.2 \pm 11.4$ & $150.1 \pm 11.2$ & 0.83 \\
\hline
\end{tabular}

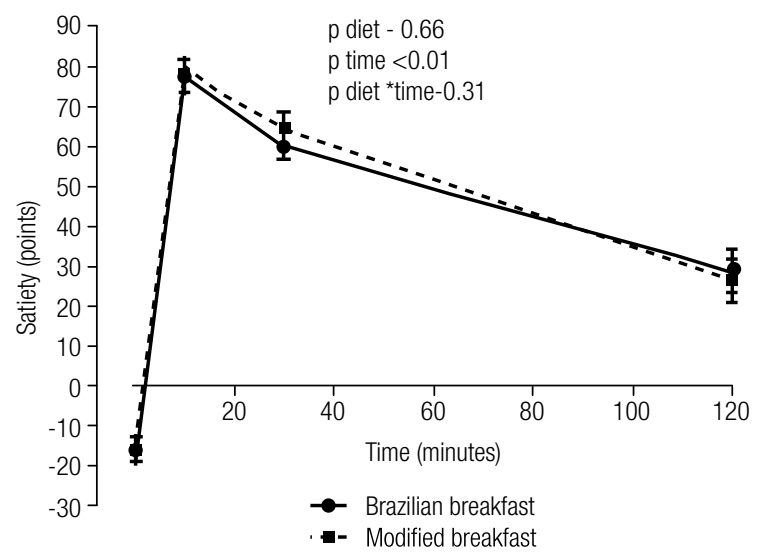

Figure 2. Mean values ( \pm SEM) of the satiety scores obtained by the SLIM scale during Brazilian and modified breakfasts.

Table 4. Differences in score of the satiety of participants after Brazilian and modified breakfasts

\begin{tabular}{lcc}
\hline & Brazilian & Modified \\
\hline Fasting & $-16.1 \pm 3.1$ & $-16.0 \pm 3.1$ \\
10 minutes & $76.5 \pm 2.8$ & $78.6 \pm 3.2$ \\
30 minutes & $59.7 \pm 3.1$ & $64.5 \pm 3.5$ \\
120 minutes & $28.6 \pm 5.4$ & $26.3 \pm 5.1$ \\
Global analysis & \multicolumn{2}{c}{0.66} \\
Effect of diet & \multicolumn{2}{c}{$<0.001$} \\
Effect of time & \multicolumn{2}{c}{0.31} \\
Interaction diet * time & \multicolumn{2}{c}{} \\
\hline
\end{tabular}

Repeated measures ANOVA.

\section{DISCUSSION}

In clinical practice, the availability of a handy tool to evaluate dietary interventions on satiety of overweight individuals is of great interest. Applying the SLIM scale, this study compared the satiety perception exhibited by distinct compositions of breakfasts to which there is evidence of deleterious or beneficial effects on the cardiometabolic profile. Isocaloric breakfasts were contrasting according to the type of fatty acids and fiber contents; the modified one showed components of the Mediterranean diet. Using this scale that quantifies satiety level, our findings did not support the hypothesis that part of the effect of these diets might occur via satiety control. Despite the benefits of the modified breakfast (blood pressure reduction and HDL-cholesterol elevation), the negative result regarding its association with satiety could indicate the limitation of the tool in detecting changes on an ample and complex regulation system of the energy balance. In addition, it is possible that a high-fat diet, independently of the fatty acids proportion, causes similar impacts in satiety perception.

The participants showed a mean body mass index compatible with class I obesity and increased waist circumference in both sexes, characteristics that make them susceptible to metabolic syndrome. Since there was no counseling for food restrictions or physical activities, substantial changes in anthropometry were not expected, despite two previous meta-analysis had shown significant Mediterranean diet-induced changes in waist circumference $(26,27)$. The lack of anthropometric changes in our study reinforces at some extent that modification in a single meal like our intervention is unable to change satiety perception to a level that would impact in body adiposity.

Reduction in blood pressure levels induced by a Mediterranean-style diet was already described $(26,28)$. Interestingly, we detected a decline in blood 
pressure after modification in a single meal for 4 weeks. Evidence obtained in an epidemiological study did not support that antihypertensive effects of Mediterranean diet would be attributed to whole grains (29) but to vegetables - due to their potassium content - and/or to the olive oil (30), which were used in our modified breakfast. Based on animal studies, it is speculated that antioxidant actions of oleic acid-rich oils (such as extra-virgin olive oil) contribute to the improvement in blood pressure levels (31).

Noteworthy that both breakfasts promote high level of satiety; in other studies, when foods were consumed mainly at dinner, the self-reported satiety was close to the scores obtained in our study (20). For both sex and after both breakfasts, mean values of satiety scores were slightly higher in women than men, and reached significance 10 minutes after the modified breakfast. Such possible difference in this perception deserves to be examined in a bigger sample. Investigations on the effects of macronutrients on satiety have shown that fat has less satietogenic properties than carbohydrates $(14,15)$. In current study, fat was offered to participants in relatively high proportions, with predominance of SFA in the Brazilian breakfast and unsaturated fatty acids in the modified one. High MUFA and PUFA contents in the later were achieved due to the presence of olive oil and peanuts, respectively. Deleterious effects of SFA in hypothalamic pathways of body weight control were described in animal models (32). Highsaturated fat diet-fed mice exhibited inflammation in hypothalamus and reduced orexigenic signals, resulting in weight gain and insulin resistance. Our findings of comparable satiety levels, following periods of exposure to distinct breakfasts for 4 weeks, do not corroborate the hypothesis that subtypes of fatty acids would induce distinct effects in central mechanisms which modulate food intake and satiety. To our knowledge, there is no similar report limiting the comparison of our results with literature. However, some investigators infused emulsion with different fatty acids contents in the ileum and verified that MUFA but not SFA infusion was associated with increased satiety (18).

The higher fiber content in the modified breakfast could also influence satiety perception, considering that some studies had reported that whole-grain foods increase satiety $(15,17,33)$, but not others (34). Facing contrasting results concerning their effect on energy intake, glucose excursion and satiety, it was desirable to expand knowledge on this aspect. The fiber content in the modified breakfast resulted in significant increase in daily consumption of fibers. Previous studies that evaluated glycemic index were also controversial regarding the inverse correlation of this parameter to satiety $(35,36)$. We did not detect correlation between the satiety scores and levels of plasma glucose nor insulin. It is possible that more substantial modifications in the meals could reach results different from ours. Also, we cannot exclude that the participants were already used to the Brazilian pattern, therefore maintaining their satiety level when this breakfast was consumed.

The modified breakfast could have provoked reductions in plasma glucose, insulin and HOMAIR. Unsaturated fatty acids in animal models and in vitro studies improve insulin signaling inducing glucose uptake (37). The effects of olive oil, due to its MUFA content, on attenuation of inflammatory status and insulin resistance are well documented $(38,39)$, and this ingredient has been recommended for prevention and control of cardiometabolic diseases $(26,40)$. The lack of HOMA-IR improvement in this study may indicate that modification of a single meal is insufficient to benefit glucose metabolism. High fiber intake has been also associated with cardioprotection mainly due to its beneficial effects on lipid metabolism $(41,42)$. Actually, only the modified breakfast induced improvement in lipid profile reflected by the elevation in HDL-cholesterol concentrations, which should be maximized due to the consumption of olive oil (43).

The reduced sample size may express difficulties of individuals to sustain lifestyle changes in real life. Despite subjectivity of satiety and intrinsic limitation of the tools to assess this perception, our findings may suggest that some of the recognized benefits of the Mediterranean diet, that should affect hormonal and neural pathways, have low impact on satiety and maybe food intake.

We conclude that isocaloric breakfasts that differ according to fatty acids content are unable to alter satiety levels, which are not correlated to glucose parameters in overweight individuals. Stronger modifications of daily meals might be necessary to differentiate satiety levels under distinct dietary patterns.

Acknowledgements: this study was supported by a grant from Fundação de Amparo à Pesquisa do Estado de São Paulo (Fapesp).

Disclosure: no potential conflict of interest relevant to this article was reported. 


\section{REFERENCES}

1. Page $\mathrm{IH}$, Stare FJ, Corcoran AC, Pollack H, Wilkinson Jr CF. Atherosclerosis and the fat content of the diet. Circulation. 1957;16(2):163-78.

2. Hu FB, Stampfer MJ, Manson JE, Rimm E, Colditz GA, Rosner BA, et al. Dietary fat intake and the risk of coronary heart disease in women. N Engl J Med. 1997;337(21):1491-9.

3. de Lorgeril M, Salen P, Martin JL, Monjaud I, Delaye J, Mamelle $\mathrm{N}$. Mediterranean diet, traditional risk factors, and the rate of cardiovascular complications after myocardial infarction: final report of the Lyon Diet Heart Study. Circulation. 1999;99(6):779-85.

4. Estruch R, Ros E, Salas-Salvadó J, Covas MI, Corella D, Arós F, et al.; PREDIMED Study Investigators. Primary prevention of cardiovascular disease with a Mediterranean diet. N Engl J Med. 2013;368(14):1279-90.

5. Lee JS, Pinnamaneni SK, Eo SJ, Cho IH, Pyo JH, Kim CK, et al. Saturated, but not $n-6$ polyunsaturated, fatty acids induce insulin resistance: role of intramuscular accumulation of lipid metabolites. J Appl Physiol (1985). 2006;100(5):1467-74.

6. Yu-Poth S, Zhao G, Etherton T, Naglak M, Jonnalagadda S, KrisEtherton PM. Effects of the National Cholesterol Education Program's Step I and Step II dietary intervention programs on cardiovascular disease risk factors: a meta-analysis. Am J Clin Nutr. 1999;69(4):632-46.

7. Martinez-Gonzalez MA, Bes-Rastrollo M. Dietary patterns, Mediterranean diet, and cardiovascular disease. Curr Opin Lipidol. 2014;25(1):20-6.

8. Rees K, Hartley L, Flowers N, Clarke A, Hooper L, Thorogood M, et al. 'Mediterranean' dietary pattern for the primary prevention of cardiovascular disease. Cochrane Database Syst Rev. 2013;8:CD009825.

9. Adam TC, Westerterp-Plantenga MS. Glucagon-like peptide-1 release and satiety after a nutrient challenge in normal-weight and obese subjects. Br J Nutr. 2005;93(6):845-51.

10. Bray GA. Afferent signals regulating food intake. Proc Nutr Soc. 2000;59(3):373-84.

11. Morton GJ, Cummings DE, Baskin DG, Barsh GS, Schwartz MW. Central nervous system control of food intake and body weight. Nature. 2006;443(7109):289-95.

12. Schneeberger M, Gomis R, Claret M. Hypothalamic and brainstem neuronal circuits controlling homeostatic energy balance. J Endocrinol. 2014; 220:T25-T46.

13. O'Keefe JH, Gheewala NM, O'Keefe JO. Dietary strategies for improving post-prandial glucose, lipids, inflammation, and cardiovascular health. J Am Coll Cardiol. 2008;51(3):249-55.

14. de Graaf C, Hulshof T, Weststrate JA, Jas P. Short-term effects of different amounts of protein, fats, and carbohydrates on satiety. Am J Clin Nutr. 1992;55(1):33-8.

15. Karhunen LJ, Juvonen KR, Huotari A, Purhonen AK, Herzig KH. Effect of protein, fat, carbohydrate and fibre on gastrointestinal peptide release in humans. Regul Pept. 2008;149(1-3):70-8.

16. Maljaars J, Peters HP, Masclee AM. Review article: The gastrointestinal tract: neuroendocrine regulation of satiety and food intake. Aliment PharmacolTher. 2007;26 Suppl 2:241-50.

17. Slavin JL. Dietary fiber and body weight. Nutrition. 2005;21(3): 411-8.

18. Maljaars J, Romeyn EA, Haddeman E, Peters HPF, Masclee AAM. Effect of fat saturation on satiety, hormone release, and food intake. Am J Clin Nutr. 2009;89(4)1019-24.

19. Alfenas RC, Mattes RD. Effect of fat sources on satiety. Obes Res. 2003;11(2):83-7.

20. Cardello AV, Schutz HG, Lesher LL, Merrill E. Development and testing of a labeled magnitude scale of perceived satiety. Appetite. 2005;44(1):1-13.

21. Flint $A$, Raben $A$, Blundell JE, Astrup A. Reproducibility, power and validity of visual analogue scales in assessment of appetite sensations in single test meal studies. Int $\mathrm{J}$ Obes Relat Metab Disord. 2000;24(1):38-48.

22. Pinheiro ABV. Tabela para avaliação de consumo alimentar em medidas caseiras. 5a ed. São Paulo: Editora Atheneu; 2004.

23. Fisberg RM, Marchioni DML, Colucci ACA. Avaliação do consumo alimentar e da ingestão de nutrientes na prática clínica. Arq Bras Endocrinol Metab. 2009;53(5):617-24.

24. Craig $C L$, Marshall $A L$, Sjöström $M$, Bauman $A E$, Booth $M L$, Ainsworth $B E$, et al. International physical activity questionnaire: 12-country reliability and validity. Med Sci Sports Exerc. 2003;35(8):1381-95.

25. Matthews DR, Hosker JP, Rudenski AS, Naylor BA, Treacher DF, Turner RC. Homeostasis model assessment: insulin resistance and beta-cell function from fasting plasma glucose and insulin concentrations in man. Diabetologia. 1985;28(7):412-9.

26. Kastorini CM, Milionis HJ, Esposito K, Giugliano D, Goudevenos JA, Panagiotakos DB. The effect of Mediterranean diet on metabolic syndrome and its components: a meta-analysis of 50 studies and 534,906 individuals. J Am Coll Cardiol. 2011;57(11):1299-313.

27. Garcia M, Shook J, Kerstetter J, Kenny A, Bihuniak J, HuedoMedinaT.The efficacy of Mediterranean diet on obesity outcomes: a meta-analysis. FASEB J. 2015;29(1):254.

28. Esposito K, Marfella R, Ciotola M, Di Palo C, Giugliano F, Giugliano $G$, et al. Effect of a mediterranean-style diet on endothelial dysfunction and markers of vascular inflammation in the metabolic syndrome: a randomized trial. JAMA. 2004;292(12):1440-6.

29. Whelton SP, Hyre AD, Pedersen B, Yi Y, Whelton PK, He J. Effect of dietary fiber intake on blood pressure: a meta-analysis of randomized, controlled clinical trials. J Hypertens. 2005;23(3):475-81.

30. PsaltopoulouT, Naska A, Orfanos P,Trichopoulos D, Mountokalakis T, Trichopoulou A. Olive oil, the Mediterranean diet, and arterial blood pressure: the Greek European Prospective Investigation into Cancer and Nutrition (EPIC) study. Am J Clin Nutr. 2004;80(4):1012-8.

31. Herrera MD, Pérez-Guerrero $C$, Marhuenda E, Ruiz-Gutiérrez V. Effects of dietary oleic-rich oils (virgin olive and high-oleicacid sunflower) on vascular reactivity in Wistar-Kyoto and spontaneously hypertensive rats. Br J Nutr. 2001;86(3):349-57.

32. De Souza CT, Araujo EP, Bordin S, Ashimine R, Zollner RL, Boschero AC, et al. Consumption of a fat-rich diet activates a proinflammatory response and induces insulin resistance in the hypothalamus. Endocrinology. 2005;146(10):4192-9.

33. Kaplan RJ, Greenwood CE. Influence of dietary carbohydrates and glycaemic response on subjective appetite and food intake in healthy elderly persons. Int J Food Sci Nutr. 2002;53(4):305-16.

34. Berti C, Riso P, Brusamolino A, Porrini M. Effect on appetite control of minor cereal and pseudocereal products. $\mathrm{Br} \mathrm{J}$ Nutr. 2005;94(5):850-8.

35. Aston LM, Stokes CS, Jebb SA. No effect of a diet with a reduced glycaemic index on satiety, energy intake and body weight in overweight and obese women. Int J Obes (Lond). 2008;32(1): 160-5.

36. McMillan-Price J, Brand-Miller J. Low-glycaemic index diets and body weight regulation. Int J Obes. 2006;30:40-6.

37. Dimopoulos N, Watson M, Sakamoto K, Hundal HS. Differential effects of palmitate and palmitoleate on insulin action and glucose utilization in rat $\mathrm{L} 6$ skeletal muscle cells. Biochem J. 2006;399(3):473-81.

38. Estruch R. Anti-inflammatory effects of the Mediterranean diet: the experience of the PREDIMED study. Proc Nutr Soc. 2010;69(3):333-40.

39. Camargo A, Delgado-Lista J, Garcia-Rios A, Cruz-Teno C, Yubero-Serrano EM, Perez-Martinez $P$, et al. Expression of 
proinflammatory, proatherogenic genes is reduced by the Mediterranean diet in elderly people. Br J Nutr. 2012;108(3):500-8.

40. Damasceno NR, Pérez-Heras A, Serra M, Cofán M, Sala-Vila A, Salas-Salvadó J, et al. Crossover study of diets enriched with virgin olive oil, walnuts or almonds. Effects on lipids and other cardiovascular risk markers. Nutr Metab Cardiovasc Dis. 2011;21 Suppl 1:S14-20.

41. Kaczmarczyk MM, Miller MJ, Freund GG. The health benefits of dietary fiber: beyond the usual suspects of type 2 diabetes mellitus, cardiovascular disease and colon cancer. Metabolism. 2012;61(8):1058-66.

42. Satija A, Hu FB. Cardiovascular benfits of dietary fiber. Curr Atheroscler Rep. 2012;14(6):505-14.

43. Bos MB, de Vries JH, Feskens EJ, van Dijk SJ, Hoelen DW, Siebelink E, et al. Effect of a high monounsaturated fatty acids diet and a Mediterranean diet on serum lipids and insulin sensitivity in adults with mild abdominal obesity. Nutr Metab Cardiovasc Dis. 2010;20(8):591-8. 